\title{
Electroneurography of the ulnar nerve in dogs
}

\author{
Ivo Hájek ${ }^{1}$, Pavel Schánilec ${ }^{1}$, Ivana Uhríková2 ${ }^{\text {, Martin Pyszko }}{ }^{3}$, Jaroslav Dufek ${ }^{4}$ \\ ${ }^{1}$ University of Veterinary and Pharmaceutical Sciences Brno, Faculty of Veterinary Medicine, Small Animal \\ Clinic, ${ }^{2}$ Department of Physiology, ${ }^{3}$ Department of Anatomy, Histology and Embryology, Brno, Czech Republic \\ ${ }^{4}$ Private Neurological Practice/Evoked Potentials Laboratory, Brno, Czech Republic \\ Received January 24, 2014 \\ Accepted July 23, 2014
}

\begin{abstract}
Electroneurography as one of the electrodiagnostic techniques is used to measure the speed of action potential which is propagated down the nerve after stimulation. It gives information about normal functioning of the peripheral nerves. The aim of this study was to evaluate the applicability of a new electroneurographic technique by performing motor nerve conduction velocity measurements in the ulnar nerve with surface stimulating electrodes in healthy dogs, to correlate the obtained data by age, limb length, rectal temperature, and sex; and to compare these results with published findings utilizing needle stimulating electrodes. The study was performed in 24 clinically healthy dogs without anaesthesia. Rectal temperatures and limb lengths were measured in all individuals. There were significant correlations among several indicators (age, rectal temperature, limb length, conduction velocity, latency and duration of compound muscle action potentials). Limb length was found to have a significant effect on the duration of the compound muscle action potential from both stimulation sites (proximal/distal; $r=0.71, r=0.68$, $P<0.01$ ), but there was no effect on the conduction velocity or amplitude of the action potentials. There was no significant difference $(P>0.05)$ in the measured indicators between males and females, even though females had a higher mean conduction velocity than males. These results prove that conduction velocity measurements in dogs could be performed non-invasively, without a danger of infection or haematomas or complications with anaesthesia, which is more favourable and time-saving for clinical practice, and more comfortable for patients.
\end{abstract}

Electrophysiology, nerve conduction velocity, electrodes, peripheral nerves, action potentials

Motor nerve conduction velocity (MNCV) testing is valuable in the detection of neuromuscular diseases: inherited and acquired polyneuropathies (Shelton et al. 2003; Gabriel et al. 2006; Vanhaesebrouck et al. 2008), general weakness (Jeffery et al. 2006), botulism (Uriarte et al. 2010), neuromuscular junction disorders (Meriggioli and Sanders 2005), polyradiculoneuritis (Hirschvogel et al. 2012), cauda equina syndrome (Sekiguchi et al. 2008), or peripheral nerves tumours (Le Chevoir 2012). Conduction velocity is defined as the speed at which an action potential propagates along a nerve. In humans, the velocity depends on many factors (age, limb temperature, etc.). Some similarities were described previously in dogs by a method which utilized needle electrodes (van Nes and van Den Brom 1986). Electroneurographic evaluation of the ulnar nerve in healthy dogs was performed and reported by several authors; however, all of them used subcutaneous electrodes to stimulate the nerves directly which is more complicated and requires general anaesthesia (Lee and Bowen 1970; Swallow and Griffiths 1977; Takakura and Inada 1983; van Nes and van Den Brom 1986). The purpose of our study was to evaluate the applicability of a new electroneurographic technique by performing nerve conduction velocity measurements with nerve stimulation by surface electrodes; to evaluate the obtained data by biological factors; and to compare the results with previous findings recorded by different methods. 


\section{Materials and Methods}

The ulnar nerve was examined electroneurographically in 24 clinically healthy dogs. Measurements of motor nerve conduction velocity were performed by an electromyographic device (Keypoint ${ }^{\circledR}$ Portable, Medtronic, Denmark) with surface bipolar stimulating electrodes with soaked felt pads. Stimulation at the proximal site was at the medial part of the elbow, at the distal site above the carpus (near the accessory carpal bone). Recording electrodes (argentchloride type of ten millimetre recording area covered with adhesive hydrogel) were placed on the palmar interossei muscles. A grounding scalp electrode was placed subcutaneously in the area of the shoulder joint. A total of 24 dogs consisting of 12 males and 12 females, aged 4 months to 12 years, of 16 different breeds (including 4 mongrel dogs) were used. Rectal temperatures and limb lengths (measured as the distance between the two stimulation sites recorded by a tape measure) were recorded in all animals. We used supramaximal stimulation during the electroneurographic measurements in all dogs, no anaesthetic protocol or sedation were used. The mean values of age, weight, rectal temperature, and limb length were $5.6 \pm 3.7$ years, $25.3 \pm 12.9 \mathrm{~kg}$, $38.3 \pm 0.5^{\circ} \mathrm{C}$, and $176 \pm 45 \mathrm{~mm}$. Moreover, for evaluating the velocity we divided the whole group into 2 groups by the limb length and 2 groups by age (groups with a limb length shorter $(n=7)$ and longer $(n=17)$ than $150 \mathrm{~mm}$, and groups of an age lower $(n=10)$ and higher $(n=14)$ than 5 years). Comparison between these groups was performed by a Mann-Whitney U test. Statistical analysis was done using the Statistica version 6.0 software (StatSoft, Inc., Tulsa, USA). The Spearman rank R test was used for correlation studies. Level of significance was set at $P<0.05$, unless specified otherwise.

\section{Results}

The mean values for stimulation, conduction velocity, latency, duration, and amplitude of the compound muscle action potentials (CMAP) are summarized. The values from the right and left side were not significantly different $(P>0.05)$, therefore they were combined. The mean value of stimulation at the proximal site was $24.8 \pm 12$ milliamperes $(\mathrm{mA})$, at the distal site $25.1 \pm 9 \mathrm{~mA}$. The mean conduction velocity was $63.0 \pm 9$ metres per second $(\mathrm{m} / \mathrm{s})$. Females had a higher mean conduction velocity $(66.8 \mathrm{~m} / \mathrm{s})$ compared to males $(59.3 \mathrm{~m} / \mathrm{s})$ but the difference was not significant $(P>0.05)$. The mean latency of CMAP from stimulation at the proximal site was $5.3 \pm 1.5$ milliseconds $(\mathrm{ms})$ and $2.4 \pm 0.6 \mathrm{~ms}$ from stimulation at the distal site. The mean CMAP durations were $3.0 \pm 0.9$ and $2.6 \pm 0.6 \mathrm{~ms}$ (proximal and distal stimulation sites). The medial amplitude of CMAP (negative phase amplitude) from stimulation at the proximal site was $3.4 \pm 2$ millivolts $(\mathrm{mV})$ and $3.9 \pm 2 \mathrm{mV}$ from stimulation at the distal site. All correlations among single indicators are summarized in Table 1 . There was a significant negative correlation between age and conduction velocity $(\mathrm{r}=-0.59, P<0.01)$, rectal temperature and CMAP latency from stimulation at the proximal site $(\mathrm{r}=-0.57, P<0.01)$ and rectal temperature and duration of the CMAP from stimulation at both sites $(\mathrm{r}=-0.55, \mathrm{r}=-0.51, P<0.01)$. Value of conduction velocity between the two groups divided by age was significantly different $(P<0.05)$. Limb length was found to have a significant effect on CMAP duration from stimulation at both sites (proximal/ distal; $\mathrm{r}=0.71, \mathrm{r}=0.68, P<0.01$ ) but there was no effect on conduction velocity or the

Table 1. Significant correlations between electrophysiological and biological indicators.

\begin{tabular}{|c|c|c|c|c|c|c|c|c|}
\hline & $\begin{array}{c}\text { Age } \\
\text { (years) }\end{array}$ & $\mathrm{RT}^{\circ} \mathrm{C}$ & $\begin{array}{l}\mathrm{LL} \\
\mathrm{mm}\end{array}$ & $\begin{array}{c}\text { Velocity } \\
\mathrm{m} / \mathrm{s}\end{array}$ & $\begin{array}{c}\text { Latency } 1 \\
\text { ms }\end{array}$ & $\begin{array}{c}\text { Latency } 2 \\
\mathrm{~ms}\end{array}$ & $\begin{array}{c}\text { Duration } 1 \\
\mathrm{~ms}\end{array}$ & $\begin{array}{c}\text { Duration } 2 \\
\mathrm{~ms}\end{array}$ \\
\hline Mean Value & $5.6 \pm 3.7$ & $38.3 \pm 0.5$ & $176 \pm 45$ & $63.0 \pm 9$ & $2.4 \pm 0.6$ & $5.3 \pm 1.5$ & $2.6 \pm 0.6$ & $3.0 \pm 0.9$ \\
\hline Correlation & velocity & $\begin{array}{c}\text { latency } 2 \\
\text { duration } 1 / 2\end{array}$ & $\begin{array}{c}\text { latency } 1 / 2 \\
\text { duration } 1 / 2\end{array}$ & age & $\begin{array}{c}\text { LL } \\
\text { duration } 1 / 2\end{array}$ & $\begin{array}{c}\text { LL } \\
\text { duration } 1 / 2\end{array}$ & $\begin{array}{c}\text { RT, LL } \\
\text { latency } 1 / 2\end{array}$ & $\begin{array}{c}\mathrm{RT}, \mathrm{LL} \\
\text { latency } 1 / 2\end{array}$ \\
\hline
\end{tabular}

RT - rectal temperature, $\mathrm{mm}$ - millimetres, $\mathrm{m} / \mathrm{s}$ - metres per second, $\mathrm{ms}$ - milliseconds, LL - limb length, Latency 1 - CMAP latency from stimulation at the distal site, Latency 2 - CMAP latency from stimulation at the proximal site, Duration 1 CMAP duration from stimulation at the distal site, Duration 2 - CMAP duration from stimulation at the proximal site, CMAP - compound muscle action potential 
CMAP amplitude. Value of conduction velocity between the two groups divided by limb length was not significantly different $(P>0.05)$. Naturally, a strong significant correlation between limb length and both latencies $(\mathrm{r}=0.88, \mathrm{r}=0.72, P<0.01)$ was detected. A significant correlation between latency and duration of the CMAP is shown in Fig. 1.

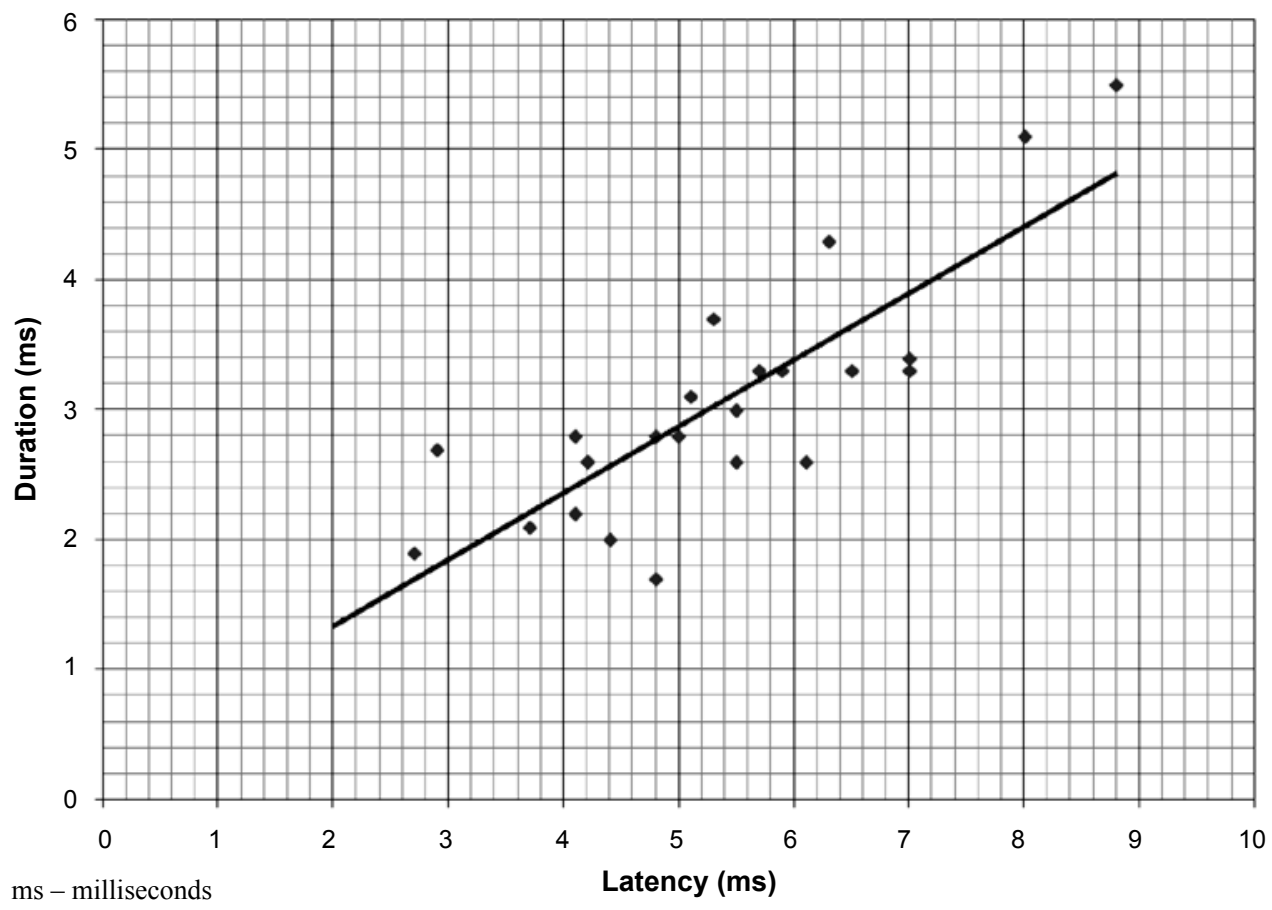

Fig. 1. An effect of limb length (latency) on duration of the compound muscle action potential

\section{Discussion}

Only a few studies focused on the methodology of motor nerve conduction velocity and the associated indicators in dogs were published long time ago; no recent studies are available because needle stimulation technique is used without follow-up research in this area (Ichiyanagi et al. 1973; Lee and Bowen 1975; Walker et al. 1979). None of them used surface electrodes for stimulation (only needle electrodes). Conduction velocity recorded in the ulnar nerve between the right and left limbs and between males and females in our study is in agreement with results reported before (Lee and Bowen 1970; Swallow and Griffiths 1977). Our results showed that the velocity measured with surface electrodes $(63 \pm 9 \mathrm{~m} / \mathrm{s})$ provided similar results to previous reports using needle electrodes $(63 \pm 4,60 \pm 1,62 \pm 6 \mathrm{~m} / \mathrm{s}$; Lee and Bowen 1970; Takakura and Inada 1983; van Nes and van Den Brom 1986). Van Nes and van Den Brom (1986) found significant differences in conduction velocity, amplitude and duration of compound muscle action potentials between short-legged and long-legged dogs. In our study, neither correlation between limb length and velocity nor CMAP amplitude was found. A significant correlation between CMAP latency (limb length) and duration of CMAP from stimulation at both proximal and distal sites was confirmed. Some differences in mean values of the 
obtained indicators were found: the CMAP amplitude in previous studies ranging from 6 to $22 \mathrm{mV}$ was higher than in our study (2-11 mV; Walker et al. 1979; van Nes and van Den Brom 1986). This can be a consequence of surface versus subcutaneous recording (much better reproducibility of amplitude and duration of the compound muscle action potential with surface recording electrodes). In addition, we confirmed lower CMAP amplitudes from stimulation at the proximal site which had been previously described (Cuddon 2002). The values of CMAP duration were similar to those published before (3.0 ms against 3.4 to $4.5 \mathrm{~ms}$; Lee and Bowen 1970; Walker et al. 1979; van Nes and van Den Brom 1986). We did not find any influence of rectal temperature (healthy dogs with normal values) on MNCV but temperature-related changes (decreased conduction in tissue hypothermia) in experimental studies were published elsewhere (Lee and Bowen 1975; Ichiyanagi et al. 1973). The values of both CMAP latencies, from stimulation at distal and proximal sites, were the same as in the conduction studies with needle electrodes ( $2 \mathrm{~ms}$ in the distal stimulation site, $5 \mathrm{~ms}$ in the proximal stimulation site; Walker et al. 1979). The correlation between age and velocity described previously was confirmed, too, but in individual cases some old dogs in our study had higher values of conduction velocity than young ones due to variability of canine population (e.g., $58.3 \mathrm{~m} / \mathrm{s}$ in an 11-year-old dog vs. $50.0 \mathrm{~m} / \mathrm{s}$ in a 3-year-old dog; Swallow and Griffiths 1977). We proved that nerve conduction measurements with surface stimulating electrodes provide comparable results to needle electrodes; the most important indicator for clinical practice, conduction velocity, is, in fact, identical. Beside conduction velocity, changes in duration of compound muscle action potential in long-legged dogs should be regarded. We found significant correlations between individual indicators in healthy dogs; some of them do not correspond to findings of studies performed by other methods and with various (higher or smaller) numbers of animals. Further studies are warranted to evaluate the potential changes of the obtained data in the groups of dogs strictly divided by age (especially young dogs).

\section{Acknowledgements}

This study was partially supported by the Ministry of Education, Youth and Sports of the Czech Republic (Institutional Research Development). The author also thanks Robert Michael Westbrook for a text revision and correction.

\section{References}

Cuddon PA 2002: Electrophysiology in neuromuscular disease. Vet Clin North Am Small Anim Pract 32: 31-62

Gabriel A, Poncelet L, Van Ham L, Clercx C, Braund KG, Bhatti S, Detilleux J, Peeters D 2006: Laryngeal paralysis-polyneuropathy complex in young related Pyrenean mountain dogs. J Small Anim Pract 47: 144-149

Hirschvogel K, Jurina K, Steinberg TA, Matiasek LA, Matiasek K, Beltrán E, Fischer A 2012: Clinical course of acute canine polyradiculoneuritis following treatment with human IV immunoglobulin. J Am Anim Hosp Assoc 48: 299-309

Ichiyanagi K, Lee D, Morris LE 1973: Nerve conduction velocity in the dog during hypothermia: effects of controlled hypercapnia. Can Anaesth Soc J 20: 519-527

Jeffery ND, Talbot CE, Smith PM, Bacon NJ 2006: Acquired idiopathic laryngeal paralysis as a prominent feature of generalised neuromuscular disease in 39 dogs. Vet Rec 158: 17

Le Chevoir M, Thibaud JM, Labruyere J, Uriarte A, De Fornel-Thibaud P, Moissonnier P, Delisle F, Blot S 2012: Electrophysiological features in dogs with peripheral nerve sheath tumours: 51 cases (1993-2010). J Am Vet Med Assoc 241: 1194-1201

Lee AF, Bowen JM 1970: Evaluation of motor nerve conduction velocity in the dog. Am J Vet Res 31: 1361-1366

Lee AF, Bowen JM 1975: Effect of tissue temperature on ulnar nerve conduction velocity in the dog. Am J Vet Res 36: 1305-1307

Meriggioli MN, Sanders DB 2005: Advances in the diagnosis of neuromuscular junction disorders. Am J Phys Med Rehabil 84: 627-638

Sekiguchi M, Aoki Y, Konno S, Kikuchi S 2008: The effects of cilostazol on nerve conduction velocity and blood flow: acute and chronic cauda equina compression in a canine model. Spine 33: 2605-2611

Shelton GD, Podell M, Poncelet L, Schatzberg S, Patterson E, Powell HC, Mizisin AP 2003: Inherited polyneuropathy in Leonberger dogs: a mixed or intermediate form of Charcot-Marie-Tooth disease? Muscle Nerve 27: 471-477 
Swallow JS, Griffiths IR 1977: Age related changes in the motor nerve conduction velocity in dogs. Res Vet Sci 23: $29-32$

Takakura Y, Inada S 1983: Motor nerve conduction velocity of the ulnar and tibial nerves and characteristics of M wave of the interosseous muscles in the adult dog. Jpn J Vet Sci 45: 413-416

Uriarte A, Thibaud JL, Blot S 2010: Botulism in 2 urban dogs. Can Vet J 51: 1139-1142

Van Nes JJ, Van Den Brom WE 1986: Electroneurographic examination of the ulnar and radial nerves in the dog: reference values, biological variation and reproducibility. Res Vet Sci 40: 189-196

Vanhaesebrouck AE, Couturier J, Cauzinille L, Mizisin AP, Shelton GD, Granger N 2008: Demyelinating polyneuropathy with focally folded myelin sheaths in a family of Miniature Schnauzer dogs. J Neurol Sci 275: $100-105$

Walker TL, Redding RW, Braund KG 1979: Motor nerve conduction velocity and latency in the dog. Am J Vet Res 40: 1433-1439 